\title{
Исследовательская статья
}

\section{Мудрость как фактор предотвращения эмоционального выгорания медицинских работников}

\author{
Н.Н. Мехтиханова ${ }^{1}$, Ю.С. Мурзина ${ }^{2}$, Ю.Е. Русакова ${ }^{2}$ \\ ${ }^{1}$ Ярославский государственный университет \\ Российская Федерация, 150003, Ярославль, ул. Советская, 14 \\ ${ }^{2}$ Тюменский государственный университет \\ Российская Федераџия, 625003, Тюмень, ул. Володарского, 6
}

\begin{abstract}
Аннотация. В статье рассматривается мудрость как внутренний ресурс медицинских работников, способный предупредить развитие нездоровых отклонений, сохранить профессиональное и жизненное долголетие. Целью работы стало изучение взаимосвязи мудрости и эмоционального выгорания у медицинского персонала. Проведен теоретический анализ изучения эмоционального выгорания медицинских работников, предложено понимание феномена мудрости, описаны зарубежные эмпирические исследования мудрости в медицинской сфере. В представленном эмпирическом исследовании для сбора данных использовались опросник «Уровень мудрости» Н.Н. Мехтихановой и методика диагностики эмоционального выгорания В.В. Бойко. Диагностика, проведенная на выборке из 184 сотрудников Областной клинической больницы г. Тюмени, показала наличие признаков эмоционального выгорания у 53,8 \% респондентов. При сравнении групп медицинских работников, имеющих разный уровень эмоционального выгорания, выявлены значимые различия по показателю мудрости. Корреляционный анализ продемонстрировал отрицательную взаимосвязь мудрости и эмоционального выгорания медицинского персонала $\left(r_{s}=-0.48, p<0.001\right)$. Сравнение групп мужчин и женщин обнаружило значимые различия по показателю мудрости и по показателю эмоционального выгорания: мудрость выше у группы мужчин, в то время как эмоциональное выгорание выше у группы женщин. Попарное сравнение по $U$-критерию Манна - Уитни выявило различия по показателю мудрости между группами младшего медицинского персонала и руководителей, а также между группами среднего медицинского персонала и руководителей. Показатель мудрости в обоих случаях выше у группы руководителей. По итогам проведенного исследования сделан вывод о том, что мудрость помогает медицинскому персоналу противостоять синдрому эмоционального выгорания. Формирование данного качества у медицинских работников позволит сохранить их психическое здоровье и профессиональное долголетие.
\end{abstract}

Ключевые слова: мудрость, эмоциональное выгорание, возрастные различия, гендерные различия, старший и младший медицинский персонал

(C) Мехтиханова Н.Н., Мурзина Ю.С., Русакова Ю.Е., 2020

(c) (i) This work is licensed under a Creative Commons Attribution 4.0 International License https://creativecommons.org/licenses/by/4.0/ 


\section{Введение}

Проблема профессионального стресса, эмоционального выгорания врачей всегда была в центре внимания ученых (Водопьянова, Старченкова, 2005; Кобякова и др., 2017; Семенова и др., 2017), но особенно остро встала в современном мире в связи с пандемией коронавируса. Тяжелые условия труда с больными COVID-19 провоцируют эмоциональные расстройства, снижают работоспособность медицинского персонала. Большое количество новых стрессогенных факторов обусловливает возникновение негативных состояний, систематическое переживание которых приводит к еще более быстрому развитию профессиональных деформаций.

По оценкам разных исследователей уровень эмоционального выгорания врачей-терапевтов в Европе и Латинской Америке варьирует от 20 до 45 \%. Опрос интернов в США выявил, что этот показатель превышает 75 \%. В 2012 г. было проведено крупномасштабное исследование специалистами из ряда ведущих клиник и университетов США. Авторы опросили 7288 врачей различных специальностей и выявили, что около половины американских врачей подвержены профессиональному выгоранию (46 \%) (Говорин, Бодагова, 2016). Высокая выраженность синдрома эмоционального выгорания (СЭВ) отмечается и у российских медицинских работников (Кобякова и др., 2017). Так, различные признаки СЭВ были отмечены у 383 обследованных врачей Забайкальского края, а эмоциональное выгорание выявлено у 67,6 \% $(n=259)$ (Говорин, Бодагова, 2016). Распространенность синдрома выгорания у врачейпсихиатров доходит до 73,2 \% (Золотухина, Шадрина 2007), у врачей-наркологов - до $79 \%$ (Лукьянов, 2008).

Исследования синдрома эмоционального выгорания ведутся в различных направлениях. Прежде всего, изучаются факторы, его детерминирующие (Бойко, 1999; Водопьянова, Старченкова, 2005; Орел, 2005). При этом основной акцент делается на деструктивных факторах, способствующих появлению и развитию синдрома. Более плодотворной стратегией представляется выявление факторов, препятствующих его формированию, что соответствует задачам позитивной психологии.

Мудрость является одним из центральных понятий позитивной психологии (Леонтьев, 2011). По данным М. Селигмана и М. Чиксентмихайи (Seligman, Csikszentmihalyi, 2000), она, как и другие феномены, рассматриваемые в этом направлении психологии, может быть той позитивной силой, которая защитит от невзгод, укрепит психологические ресурсы, предупредит развитие нездоровых отклонений у человека. Мудрость может выполнить профилактическую работу, которая является главной задачей позитивной психологии.

Исследования проблемы эмоционального выгорания в медицинской cфере. В отечественной психологии исследованиями синдрома эмоционального выгорания занимались В.А. Бодров, В.В. Бойко, М.В. Борисова, Н.Е. Водопьянова, Л.Г. Дикая, О.Н. Доценко, В.Е. Леонова, В.В. Лукьянов, А.А. Обознов, В.Е. Орел и многие другие, за рубежом - С. Джексон, К. Маслач, Г. Фрейденбергер и др.

Первоначально эмоциональное выгорание у медицинских работников изучалось в связи профессиональным стрессом как одно из главных и пагуб- 
ных его последствий. Затем тема СЭВ приобрела самостоятельное значение и стала активно разрабатываться в различных направлениях. Изучались симптоматика, течение, детерминация СЭВ у врачей различных специальностей неврологов, участковых терапевтов, гигиенистов, анестезиологов-реаниматологов, стоматологов, наркологов, психиатров и др. (Абдуллаева, 2013; Бектасова и др., 2016; Борисова и др., 2019; Говорин, Бодагова, 2016; Золотухина, Шадрина, 2007; Зыкова, Горбунова, 2020; Кобякова и др., 2017; Лукьянов, 2008; Мурашкин, Шаршакова, 2020; Панкова и др., 2019; Семенова и др., 2017; Чутко, Козина, 2013 и др.). На основе этих исследований были созданы эффективные программы по снижению уровня выгорания (Водопьянова, 2013).

В контексте нашей работы особый интерес представляют исследования детерминации СЭВ. В. В. Бойко выделяет ряд внешних и внутренних факторов, которые провоцируют выгорание (Бойко, 1999). К внешним детерминантам выгорания медицинских работников относятся традиционные для многих видов профессий: перегрузка работой, средний или низкий уровень оплаты труда и др. Описываются также специфические для медицинской сферы факторы - высокая степень эмоциональной насыщенности работы, высокий уровень ответственности за результаты труда, обязательная ротация смен, загруженность из-за нехватки персонала, уход за неизлечимо больными и др.

Несмотря на многообразие внешних факторов, ведущая роль в развитии выгорания отводится внутренним факторам - личностным характеристикам работника: мотивационной сфере, характерологическим и темпераментальным свойствам, особенностям самооценки и саморегуляции, стилевым особенностям поведения и деятельности и многим другим (Водопьянова, Старченкова, 2005; Обознов, Доценко, 2013; Орел 2005). Их изучению посвящено огромное количество эмпирических работ. Среди них особенно перспективной представляется попытка найти универсальные факторы выгорания те характеристики личности, которые занимают в ее структуре доминирующее и устойчивое положение. К таковым, например, можно отнести ценностномотивационные характеристики специалиста, отражающие направленность его личности (Обознов, Доценко, 2013).

Гораздо меньше исследований выполнено с целью изучения личностных факторов, препятствующих выгоранию. В то же время для разработки эффективных программ предотвращения и коррекции негативных последствий трудовой деятельности необходим комплексный подход - с учетом позитивных сторон психической жизни (Водопьянова, Шестакова, 2014; Полунина, 2013). Именно поэтому востребованным практикой становится изучение феномена мудрости в контексте профессиональной деятельности. В отечественной науке такого рода эмпирические исследования отсутствуют.

Исследования проблемы мудрости в медицинской сфере. Психологи полагают, что работа в современной ситуации требует предвосхищения событий, адекватного восприятия, понимания обстоятельств, спокойного отношения к действительности, оптимальных действий в сложившихся условиях. Все перечисленное является, по сути, признаками мудрости - комплексного свойства личности, помогающего преодолевать трудности с наименьшими потерями для психоэмоционального состояния, сохраняюще- 
го профессиональную самоотдачу. На наш взгляд, можно выделить основные функции мудрости: помощь в адаптации и творческом решении сложных проблем, способствование успешности в профессии, сохранение душевного здоровья и т. д.

Долгое время термин «мудрость» использовался главным образом в философии и житейской практике. В обыденном сознании чаще всего мудрость понимается как нечто далекое от повседневной жизни, от реального воплощения в конкретном человеке. Возможно, именно поэтому психологическая наука практически до XX века не обращалась к данной теме.

В первых психологических теоретических работах мудрость была описана как идеальная конечная точка человеческого развития. Эту идею сформулировал С. Холл в фундаментальном труде «Старение» (Hall, 1922), в котором связывал развитие мудрости с появлением в позднем взрослом возрасте философского спокойствия, беспристрастности и желания извлечь моральные уроки. Теоретические психологические концепции мудрости разрабатывали К.Г. Юнг и Э. Эриксон, но только с середины 80-х годов XX века в зарубежной психологии стали эмпирически изучать мудрость. В отечественной психологии мудрость рассматривалась главным образом в теоретическом плане (Л.И. Анцыферова, Д.А. Леонтьев, М.А. Холодная, Г.В. Ожиганова, А.С. Огнев, Н.Н. Мехтиханова, Е.А. Никитина). Эмпирические исследования мудрости малочисленны в силу отсутствия адекватных и надежных инструментов ее исследования.

В русскоязычном социокультурном контексте Н.Н. Мехтихановой и ее коллегами проанализированы и обобщены многие теоретические вопросы феномена мудрости, а также разработан опросник «Уровень мудрости». Под термином «мудрость» авторы понимают особое когнитивное образование субъекта, формирующееся в ходе его жизненного пути, отражающее результаты функционирования практического интеллекта во взаимосвязи с личностными чертами, направляющее и оптимизирующее индивидуальное развитие и обеспечивающее успешность в практической стороне жизни (Mехтиханова, Смульсон, 2013).

Зарубежные исследователи включают мудрость в перечень наиболее важных качеств успешного врача и связывают ее с оптимальными стратегиями совладания со стрессом, а также с предупреждением эмоционального выгорания. Мудрость рассматривается как один из фундаментальных компонентов профессионализма медицинских работников (Byyny et al., 2015).

Считается, что мудрость составляет основу искусства медицины. Мудрость - это критическая оценка знаний и умение отбирать и применять их с использованием не только научных, но и морально-этических, социальных и финансовых критериев. Она включает в себя личный опыт, суждение, осмотрительность, сострадание, «клинический инстинкт» (Papagiannis, 2017). Среди 23 характеристик хорошего врача, установленных в исследовании Price et al. (1971), мудрость занимает одно из первых мест. Перечислим несколько из этих характеристик: 1) хорошее клиническое суждение; 2) современные знания в соответствующей области; 3) знания и способность провести тщательное обследование и прийти к заключению относительно диагноза, лечения и свя- 
занных с ними проблем; 4) мудрость и вдумчивость: способность проникать в суть проблемы и отличать важные факты от менее важных; 5) адаптивность: способность адаптироваться к изменяющимся знаниям и условиям.

В свете возросшей значимости гуманистического подхода в медицинских услугах исследователи J.C. Rogers и L. Coutts (2000) описали поведенческий портрет врача: 1) уважает точку зрения пациента и учитывает его мнение; 2) заботится о психологическом благополучии пациента; 3) рассматривает пациента как уникальную индивидуальность; 4) относится к пациенту в контексте его семьи, социального и физического окружения; 5) обладает хорошей коммуникативной способностью и навыками слушания; 6) порождает доверие и уверенность; 7) демонстрирует теплоту и сострадание; 8) является эмпатическим (Rogers, Coutts, 2000).

L.A. Haggerty и P. Grace (2008) определили ключевые компоненты клинической мудрости в работе медсестры: уравновешивание и обеспечение блага другого и самого себя, общее благо, использование интеллекта и аффекта в решении проблем, а также демонстрация опытного молчаливого знания в проблемных ситуациях. Y. Christley (2012) с коллегами дополнили список характеристик для мудрой медицинской сестры: опыт, рефлексия, забота, сострадание и сопереживание. По мнению Р. Benner (2000) мудрость медицинской сестры основана на клиническом суждении и подходе «мышление в действии», который включает интуицию, эмоции и чувства. S.A. Matney et al. (2011) описали мудрость как применение опыта, интеллекта, творчества и знания, опосредованные ценностями, направленными на достижение общего блага. B развитие этой темы S.A. Matney et al. (2014) пишут, что мудрость проявляется в способности медработника добавлять опыт и интуицию к ситуации, а также применять знания с сочувствием, пониманием и состраданием.

Таким образом, медицинские работники должны обладать характеристиками, которые и составляют содержание конструкта «мудрость» в современной психологии (Ardelt, 2003; Baltes, Smith, 2008; Мехтиханова, 2010, 2013 и др.) Ожидается, что они будут иметь фактические и процедурные знания о том, как диагностировать и лечить состояния, обладать умением критически мыслить, искать причины и доказательства, будут заботливыми и сострадательными людьми, видящими пациентов такими, какие они есть в своем социальном/культурном/экономическом/психологическом плане, прислушивающимися к потребностям пациентов, четко общающимися с ними, соблюдающими трудовую этику, обучающимися на протяжении всей жизни (Kulatunga-Moruzi, Norman, 2002; Rogers, Coutts, 2000).

Мудрость рассматривается как условие успешной трудовой деятельности, препятствие эмоциональному выгоранию. Так, W. Budziński et al. (2018) показали, что наиболее низкий риск в развитии выгорания в карьере врача связан с такими ценностями, как семейная безопасность, свобода, счастье, зрелая любовь, самоуважение, социальное признание и мудрость. S. Mangione et al. (2018) в своих исследованиях проверили гипотезу о том, что студенты-медики, изучающие и гуманитарные науки, а не только медицинские, будут показывать более высокие уровни положительных качеств, необходимых для будущего врача. Исследование обнаружило, что воздействие литературы, музыки, театра и изобразительного искусства имеет значимую корреляцию с положитель- 
ными личными качествами студентов - будущих врачей: сочувствие, терпимость к двусмысленности, мудрость и т. п., а также обратную корреляцию с компонентами СЭВ. Доказывается, что мудрость вполне может быть единственной чертой, которая включает в себя все другие черты хорошего врача: эмпатию, открытость возможностям, эмоциональную устойчивость, внимательность, смирение, альтруизм, умение учиться у жизни, чувство юмора. Авторы считают, что развитие мудрости должно лежать в основе профилактики эмоционального выгорания.

J.M. Smith (2020) видит в коучинге возможность формирования профессиональной мудрости и проницательности, что помогает в управлении эмоциональным выгоранием и оздоровлении хирурга. Т.J. Clouston (2019) констатирует, что существующие в Великобритании принципы повышения производительности труда медперсонала неэффективны, так как не позволяют сотрудникам справляются с растущим уровнем стресса и дисбалансом между работой и личной жизнью. Т.J. Clouston предлагает четыре стратегии, как он сам их называет - «жемчужины мудрости», для снятия стресса в коллективе медучреждения: 1) возможность самостоятельного выбора рабочей нагрузки; 2) учет семейных ценностей персонала; 3) поддерживающие отношения на рабочем месте; 4) решение оргконфликтов через согласование с личными ценностями. J. Levey и M. Levey (2019), говоря о VUCA-мире, предлагают противопоставить ему мудрость и осознанность как противоположный эволюционный импульс. Они пишут о важности развития мудрости у руководителей медучреждений.

Таким образом, в современных зарубежных исследованиях мудрость выступает в качестве обязательного личностного качества как для сотрудников, так и для руководителей в сфере медицинского обслуживания. Мудрость рассматривается как фундамент технологии решения конфликтов и заботы о медперсонале, лежит в основе профилактики эмоционального выгорания.

Отечественных исследований мудрости у медицинских работников, в частности в контексте эмоционального выгорания, не проводилось. Поэтому исследования проблемы взаимосвязи мудрости и эмоционального выгорания на российских выборках достаточно актуальны. В связи с этим целью нашей работы является установление взаимосвязи мудрости и эмоционального выгорания у работников российского здравоохранения.

\section{Процедура и методы исследования}

В феврале - марте 2020 года нами было реализовано исследование взаимосвязи уровня мудрости и эмоционального выгорания у медицинских работников. Для этого была собрана выборка численностью 184 человека, состоящая из сотрудников Областной клинической больницы г. Тюмени. Данные сотрудники на тот момент времени не принимали участие в лечении больных с инфекцией COVID-19. Возрастной состав группы распределился почти равномерно: 25-35 лет - 26,6 \%, 35-45 лет - 23,9 \%, 45-55 лет - 25,2 \%, 55-65 лет - 13,6 \%, старше 65 лет - 10,7 \%. По полу состав группы оказался неравномерным: женщины составили 87,5 \%, а мужчины - 12,5 \%. Распределение группы по стажу работы: до 5 лет - 16,3 \%, от 5 до 10 лет - 15,8 \%, 
от 10 до 15 лет - 13,5\%, от 15 до 20 лет - 14,7 \% и свыше 20 лет - 39,7\%. В группе сложилось следующее соотношение должностей: руководители 7,6 \%, врачи - 23,9 \%, средний медицинский персонал - 58,7 \%, младший медицинский персонал - 9,8 \%.

В ходе исследования были использованы следующие психодиагностические методики.

1. Опросник «Уровень мудрости» (Мехтиханова, Смульсон, 2013). В ходе разработки данной методики использовались неявные теории мудрости (качества мудрого человека, отраженные в пословицах, поговорках и сказках, а также взятые из современных представлений о мудрости) и явные теории (уже существующие авторские концепции мудрости). Полученные качества мудрого человека были классифицированы на три категории: когнитивные, личностные и поведенческие, что послужило основой утверждений, составляющих методику. К когнитивной составляющей относятся такие показатели, как опыт, базовые знания о способах выполнения действия, самопознание, обучаемость, оперативное использование информации и др.; к личностной составляющей - толерантность, альтруизм, организованность, любознательность и др.; к поведенческой составляющей - применение знаний на практике, умение давать советы, воплощение новых идей, общительность и др.

Опросник состоит из 63 пунктов, с которыми респондент должен выразить степень своего согласия по 5-балльной шкале Ликерта. Приведем примеры прямых и обратных утверждений, содержащихся в методике:

- Часто бывает, что я забываю что-то важное.

- Обычно мне нетрудно реализовывать свои идеи.

- Если кто-то поступил со мной грубо, я отвечу тем же.

- Решая проблемы, я часто забываю учесть мелкие детали.

- Необходимость сделать что-то сложное и важное тяготит меня.

- Я предпочитаю просить советы, а не давать их.

- Я не считаю, что в споре может быть только одна правильная точка зрения.

Подсчет баллов производится с помощью ключа простым суммированием. Все утверждения составляют единственную шкалу, формирующую один итоговый показатель. Максимально возможное значение по шкале - 325 баллов.

Методика прошла необходимые психометрические процедуры: стандартизацию, проверку надежности и валидности. Надежность методики определялась, в частности, через меру согласованности результатов. Для оценки гомогенности (внутренней согласованности) пунктов теста был использован традиционный коэффициент $\alpha$ Кронбаха. Результаты исследования авторов методики $(n=382)$ показали высокую надежность-согласованность пунктов опросника: $\alpha$ Кронбаха = 0,91. Данные, полученные в настоящем исследовании на выборке медицинских работников, подтвердили надежность и согласованность опросника: $\alpha$ Кронбаха составила 0,90 .

2. Методика диагностики эмоционального выгорания В.В. Бойко (Бойко, 1999) позволяет диагностировать симптомы эмоционального выгорания и определить фазу его развития (напряжение, резистенщия, истощение). Максимально возможное значение для каждой фазы - 120 баллов. Данная методика широко используется в отечественных исследованиях СЭВ в различных выборках. 
Для обработки результатов были использованы статистические методы: $U$-критерий Манна - Уитни, $H$-критерий Краскела - Уоллиса, ранговый корреляционный анализ Спирмена. Применялись статистические пакеты Statistica 8.0, IBM SPSS Statistics 17.0.

\section{Результаты исследования и их обсуждение}

Анализ результатов по опроснику диагностики эмоционального выгорания В.В. Бойко выявил медицинских работников с разным уровнем эмоционального выгорания, которых можно разделить на три группы:

1) специалисты с высоким уровнем эмоционального выгорания (15 человек), у которых сформировались все три фазы СЭВ;

2) специалисты с низкими показателями эмоционального выгорания (85 человек), у которых не сформировано ни одной фазы СЭВ, у них проявилось незначительное повышение показателей по отдельным симптомам;

3) специалисты с признаками эмоционального выгорания (84 человека или $45 \%$ всех обследованных), выразившимися либо в сформированности одной-двух фаз СЭВ, либо в наличии фазы в стадии формирования.

В основном у респондентов диагностируется фаза резистенции (сопротивления), далее идут истощение и тревожное напряжение. Это проявляется в сложностях во взаимодействии по вопросам организации корпоративных изменений, сопротивлении при внедрении новшеств в привычный трудовой распорядок, трудностях в установлении контактов, сотрудничестве по вопросам, не касающимся напрямую работы, например, профессионального обучения, наставничества, формирования кадрового резерва и т. д.

При объединении первой и третьей группы наличие признаков эмоционального выгорания фиксируется у 53,8 \% респондентов. Таким образом, каждый второй человек в группе всех обследованных медицинских работников имеет защитные реакции в форме СЭВ в большей или меньшей степени. Эти результаты совпадают с данными многочисленных исследований СЭВ у работников социономических профессий, выполненных в разное время в нашей стране и за рубежом (Бойко, 1999; Водопьянова, Старченкова, 2005; Кобякова и др., 2017; Лукьянов, 2008; Орел, 2005; Shih et al., 2016; Mangione et al., 2018; Wang, 2020 и др.).

При сравнении групп мужчин и женщин выявлены значимые различия по показателю эмоционального выгорания (табл. 1).

Описательная статистка и статистическая оценка различий по показателю эмоционального выгорания между группами мужчин и женщин

[Table 1. Means (M), standard deviations (SD) and Mann - Whitney U-test between indicators of emotional burnout in men and women]

\begin{tabular}{|c|c|c|c|c|c|c|}
\hline \multirow[t]{2}{*}{ Показатель } & \multicolumn{2}{|c|}{ Мужчины } & \multicolumn{2}{|c|}{ Женщины } & \multirow[t]{2}{*}{ U-критерий } & \multirow[t]{2}{*}{ Уровень значимости, $p$} \\
\hline & $M$ & $S D$ & $M$ & $S D$ & & \\
\hline $\begin{array}{c}\text { Эмоциональное } \\
\text { выгорание }\end{array}$ & 74,87 & 56,88 & 107,89 & 66,39 & 1253.0 & 0.013 \\
\hline
\end{tabular}


Как следует из табл. 1, показатель эмоционального выгорания выше в группе женщин. Действительно, помимо рабочей нагрузки, женщины выполняют функции по ведению домашнего хозяйства, ухода за детьми и т. п. Часто это трудно сочетать с высокой стрессогенностью работы медперсонала, что ускоряет развитие и усугубляет СЭВ. Как отмечают L. Wang et al. (2020) двойное давление работы и семьи делает женщин-врачей менее счастливыми и более склонными к выгоранию.

Достоверных различий по уровню эмоционального выгорания между респондентами различных возрастов получено не было, но наблюдается тенденция, что выгорание происходит в возрастном диапазоне от 25 до 55 лет. У работников старше 55 лет СЭВ практически отсутствует. Вероятно, работать в области медицины в пенсионном и предпенсионном возрасте остаются только сотрудники, устойчивые к выгоранию. Это свидетельствует о сформированной у них эффективной системе саморегуляции. По данным Н.Е. Водопьяновой и Е.С. Старченковой (2005), влияние возраста на эффект выгорания неоднозначно. К нему предрасположены лица не только старшего, но и молодого возраста.

При сравнении групп медицинских работников, занимающих разные должности (немедицинский специалист, младший медицинский персонал, средний медицинский персонал, врачебный персонал, руководители), наибольший уровень выгорания выявлен среди медицинских сестер. Этот факт согласуется с данными многих исследователей (Золотухина, Шадрина, 2007; Christley et al., 2012; Haggerty, Grace, 2008; Matney et al., 2014 и др.) и объясняется чрезвычайно неблагоприятными внешними детерминантами деятельности этой группы работников.

У медицинских работников, имеющих разный стаж работы, значимых различий в показателях эмоционального выгорания выявлено не было. Аналогичные данные получены и в других исследованиях (Абдуллаева, 2013). По всей видимости, продолжительность работы не определяет СЭВ, он может наступить и в начале, и в середине трудовой деятельности, в большей мере на это влияют другие факторы.

Анализ результатов по опроснику «Уровень мудрости» показал, что при сравнении групп мужчин и женщин выявлены значимые различия по показателю мудрости (табл. 2).

Таблица 2

Описательная статистка и статистическая оценка различий по показателю мудрости между группами мужчин и женщин

[Table 2. Means (M), standard deviations (SD) and Mann - Whitney U-test between indicators of wisdom in men and women]

\begin{tabular}{|c|c|c|c|c|c|c|}
\hline \multirow[t]{2}{*}{ Показатель } & \multicolumn{2}{|c|}{ Мужчины } & \multicolumn{2}{|c|}{ Женщины } & \multirow[t]{2}{*}{ U-критерий } & \multirow[t]{2}{*}{ Уровень значимости, $p$} \\
\hline & $M$ & $S D$ & $M$ & $S D$ & & \\
\hline Уровень мудрости & 239,61 & 26,66 & 229,91 & 22,95 & 1267.50 & 0.016 \\
\hline
\end{tabular}

Результаты, представленные в табл. 2, свидетельствуют о том, что показатель мудрости выше в группе мужчин. Большинство мужской группы 82,6 \% составляют врачи. В женской группе большая часть 65,8 \% представлена средним медицинским персоналом. Поскольку группа мужчин и женщин 
неравнозначна по количеству и разнородна по составу, для более точного сравнения уровня мудрости по полу мы взяли две идентичные по должности группы из нашей выборки «Врачи мужчины» - 19 человек и «Врачи женщины» - 25 человек. В группе врачей так же, как и в общей группе, результаты распределения по уровню мудрости говорят о том, что среди мужчин обладателей высокого уровня мудрости больше, чем среди женщин. Данный факт не соответствует данным, выявленным ранее в исследованиях отечественных ученых (Мехтиханова, 2010). Обсуждение гендерных аспектов проблемы мудрости в зарубежных эмпирических работах практически отсутствуют.

При сравнении групп респондентов разного возраста значимых различий по показателю мудрости выявлено не было. Это еще раз подтверждает многократно выявленный наукой, однако противоречащий житейским представлениям факт, что мудрость присуща не только людям старшего возраста, но может проявляться в любом возрасте (Мехтиханова, Смульсон, 2013; Baltes, Smith, 2008). Мудрость, как и кристаллический интеллект, удерживает свой уровень, начиная с ранней взрослости и вплоть до глубокой старости. Пожилой возраст не может ни приносить мудрость, ни отбирать ее.

Множественное сравнение с помощью $H$-критерия Краскела - Уоллиса показало, что группы медицинских работников, занимающих разные должности (немедицинский специалист, младший медицинский персонал, средний медицинский персонал, врачебный персонал, руководители) значимо различаются по показателю мудрости (табл. 3).

Таблица 3
Описательная статистка и статистическая оценка различий по показателю мудрости между группами медицинских работников, занимающих разные должности [Table 3. Means (M), standard deviations (SD) and Kruskal - Wallis $\boldsymbol{H}$-test between indicators of wisdom in medical workers holding different positions]

\begin{tabular}{|c|c|c|c|c|c|c|c|c|c|c|c|c|}
\hline \multirow[t]{2}{*}{$\begin{array}{c}\text { Показа- } \\
\text { тель }\end{array}$} & \multicolumn{2}{|c|}{ 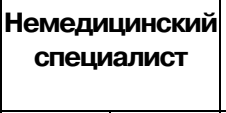 } & \multicolumn{2}{|c|}{$\begin{array}{c}\text { Младший } \\
\text { медицинский } \\
\text { персонал }\end{array}$} & \multicolumn{2}{|c|}{$\begin{array}{c}\text { Средний } \\
\text { медицинский } \\
\text { персонал }\end{array}$} & \multicolumn{2}{|c|}{$\begin{array}{c}\text { Врачебный } \\
\text { персонал }\end{array}$} & \multicolumn{2}{|c|}{ Руководители } & \multirow{2}{*}{\multicolumn{2}{|c|}{$\begin{array}{l}\text { H-критерий, } \\
\text { уровень зна- } \\
\text { чимости, p }\end{array}$}} \\
\hline & $M$ & & $M$ & $S D$ & $M$ & $S D$ & $M$ & $S D$ & $M$ & $S D$ & & \\
\hline $\begin{array}{c}\text { Уровень } \\
\text { мудрости }\end{array}$ & 232,17 & 23,80 & 230,42 & 12,87 & 227,45 & 21,60 & 234,74 & 28,91 & 248,50 & 20,36 & 13.29 & 0.01 \\
\hline
\end{tabular}

Проведенное далее попарное сравнение по $U$-критерию Манна - Уитни (табл. 4) выявило различия по показателю мудрости между группами младшего медицинского персонала и руководителей $(U=31.00, p=0.007)$, а также между группами среднего медицинского персонала и руководителей $(U=326.00$, $p<0.001)$.

Из данных табл. 4 следует, что показатель мудрости в обоих случаях выше у группы руководителей. Вместе с тем между группой врачей и группой руководителей значимых различий установлено не было. Выявленные нами факты могут быть объяснены спецификой выборки - группу руководителей и врачей составили лица с высшим профессиональным образованием. В работах P.B. Baltes и J. Smith (2008) однозначно установлена положительная связь мудрости и интеллекта, который, в свою очередь, коррелирует с уровнем образования. 
Описательная статистка и статистическая оценка различий по показателю мудрости между группами медицинских работников, занимающих разные должности [Table 4. Means (M), standard deviations (SD) and Mann - Whitney U-test between indicators of wisdom in medical workers holding different positions]

\begin{tabular}{|c|c|c|c|c|c|c|c|}
\hline \multicolumn{2}{|c|}{$\begin{array}{l}\text { Уровень мудрости } \\
\text { младшего } \\
\text { медицинского } \\
\text { персонала }\end{array}$} & \multicolumn{2}{|c|}{$\begin{array}{c}\text { Уровень мудрости } \\
\text { руководителей }\end{array}$} & \multicolumn{2}{|c|}{$\begin{array}{c}\text { Уровень мудрости } \\
\text { среднего } \\
\text { медицинского } \\
\text { персонала }\end{array}$} & \multirow[t]{2}{*}{$\begin{array}{c}\text { Сравниваемые } \\
\text { группы }\end{array}$} & \multirow[t]{2}{*}{$\begin{array}{c}U \text {-критерий, } \\
\text { уровень } \\
\text { значимости, } p\end{array}$} \\
\hline$M$ & $S D$ & $M$ & $S D$ & $M$ & $S D$ & & \\
\hline \multirow{2}{*}{230,42} & \multirow{2}{*}{12,87} & \multirow{2}{*}{248,50} & \multirow{2}{*}{20,36} & \multirow{2}{*}{227,45} & \multirow{2}{*}{21,60} & $\begin{array}{c}\text { Младший меди- } \\
\text { цинский персонал } \\
\text { и руководители }\end{array}$ & $\begin{array}{l}U=31.00 \\
p=0.007\end{array}$ \\
\hline & & & & & & $\begin{array}{c}\text { Средний меди- } \\
\text { цинский персонал } \\
\text { и руководители }\end{array}$ & $\begin{array}{c}U=326.00 \\
p<0.001\end{array}$ \\
\hline
\end{tabular}

Таблица 5

Описательная статистка и статистическая оценка различий по показателю мудрости между группами медицинских работников, занимающих разные должности [Table 5. Means (M), standard deviations (SD) and Kruskal - Wallis H-test

between indicators of wisdom in medical workers with different levels of emotional burnout]

\begin{tabular}{|c|c|c|c|c|c|c|c|}
\hline \multirow[t]{2}{*}{ Показатель } & \multicolumn{2}{|c|}{$\begin{array}{c}\text { Группа с высоким } \\
\text { уровнем эмоцио- } \\
\text { нального выгорания }\end{array}$} & \multicolumn{2}{|c|}{$\begin{array}{c}\text { Группа со средним } \\
\text { уровнем эмоцио- } \\
\text { нального выгорания }\end{array}$} & \multicolumn{2}{|c|}{$\begin{array}{c}\text { Группа с низким } \\
\text { уровнем эмоцио- } \\
\text { нального выгорания }\end{array}$} & \multirow[t]{2}{*}{$\begin{array}{c}\text { H-критерий, } \\
\text { уровень } \\
\text { значимости, } p\end{array}$} \\
\hline & $M$ & $S D$ & $M$ & $S D$ & $M$ & $S D$ & \\
\hline $\begin{array}{c}\text { Уровень } \\
\text { мудрости }\end{array}$ & 219,29 & 24,13 & 230,44 & 21,00 & 244,05 & 18,65 & $\begin{array}{c}H=33.10 \\
p<0.001\end{array}$ \\
\hline
\end{tabular}

Таблица 6

Описательная статистка и статистическая оценка различий по показателю мудрости между группами медицинских работников с разным уровнем эмоционального выгорания [Table 6. Means (M), standard deviations (SD) and Mann - Whitney U-test

between indicators of wisdom in medical workers with different levels of emotional burnout]

\begin{tabular}{|c|c|c|c|c|c|c|c|}
\hline \multicolumn{2}{|c|}{$\begin{array}{c}\text { Уровень мудрости } \\
\text { группы с низким } \\
\text { уровнем выгорания }\end{array}$} & \multicolumn{2}{|c|}{$\begin{array}{c}\text { Уровень мудрости } \\
\text { группы со средним } \\
\text { уровнем выгорания }\end{array}$} & \multicolumn{2}{|c|}{$\begin{array}{l}\text { Уровень мудрости } \\
\text { группы с высоким } \\
\text { уровнем выгорания } \\
\end{array}$} & \multirow[t]{2}{*}{$\begin{array}{c}\text { Сравниваемые } \\
\text { группы }\end{array}$} & \multirow[t]{2}{*}{$\begin{array}{c}U \text {-критерий, } \\
\text { уровень } \\
\text { значимости, p }\end{array}$} \\
\hline$M$ & $S D$ & $M$ & $S D$ & $M$ & $S D$ & & \\
\hline \multirow{3}{*}{244,05} & \multirow{3}{*}{18,65} & \multirow{3}{*}{230,44} & \multirow{3}{*}{21,00} & \multirow{3}{*}{219,29} & \multirow{3}{*}{24,13} & $\begin{array}{c}\text { Группы с низким } \\
\text { и средним уровнем } \\
\text { эмоционального } \\
\text { выгорания }\end{array}$ & $\begin{array}{c}U=1201.00 \\
p=0.001\end{array}$ \\
\hline & & & & & & $\begin{array}{c}\text { Группы с низким } \\
\text { и высоким уровнем } \\
\text { эмоционального } \\
\text { выгорания }\end{array}$ & $\begin{array}{c}U=758.00 \\
p<0.001\end{array}$ \\
\hline & & & & & & $\begin{array}{c}\text { Группы со средним } \\
\text { и высоким уровнем } \\
\text { эмоционального } \\
\text { выгорания }\end{array}$ & $\begin{array}{c}U=1365.00 \\
p=0.008\end{array}$ \\
\hline
\end{tabular}

Сопоставление групп медицинских работников, имеющих разный уровень эмоционального выгорания (низкий, средний, высокий) по $H$-критерию Краскела - Уоллиса выявило значимые различия по показателю мудрости (табл. 5).

При попарном сравнении по $U$-критерию Манна - Уитни (табл. 6) установлены различия по показателю мудрости между группами с высоким и средним уровнем эмоционального выгорания, средним и низким уровнем эмоционального выгорания, высоким и низким уровнем эмоционального выгорания. 
Как следует из табл. 6, выше всего показатель мудрости у группы медицинских работников с низким уровнем эмоционального выгорания, ниже всего показатель мудрости у работников с высоким уровнем эмоционального выгорания. Это согласуется с данными исследования Н.Н. Мехтихановой (2013). Было доказано, что испытуемые с высоким уровнем мудрости обладают высокой нервно-психологической, эмоциональной устойчивостью, уравновешенностью, эффективной поведенческой регуляцией, умением управлять своими эмоциями, адекватной самооценкой и восприятием действительности. Они легко и адекватно ориентируются в ситуации, вырабатывают стратегию своего поведения и социализации, быстро адаптируются в новых условиях. Отмечается коммуникабельность, умение взаимодействовать с окружающими, социальная направленность. Все это помогает избегать конфликтных ситуаций, справляться с возникающими трудностями и не терять работоспособность.

Анализ корреляций между показателями эмоционального выгорания и уровнем мудрости (табл. 7) выявил, что уровень мудрости отрицательно связан с эмоциональным выгоранием по всей выборке. Кроме этого, показатель мудрости отрицательно связан с показателем эмоционального выгорания в группе с высоким уровнем выгорания и в группе с низким уровнем выгорания, а также в группе врачебного персонала $(r=-0.76, p=0.002)$.

Таблица 7

Значимые коэффициенты корреляций Спирмена между показателями мудрости и эмоционального выгорания в разных группах [Table 7. Significant Spearman's correlations between the indicators of wisdom and emotional burnout in different groups]

\begin{tabular}{lc}
\hline \multicolumn{1}{c}{ Группа испытуемых } & $\begin{array}{c}\text { Показатель корреляции, } \\
\text { уровень значимости, } \boldsymbol{p}\end{array}$ \\
\hline Вся выборка & $r=-0.48, p<0.001$ \\
\hline Группа испытуемыхс низким уровнем эмоционального выгорания & $r=-0.36, p=0.003$ \\
\hline Группа испытуемых с высоким уровнем эмоционального выгорания & $r=-0.29, p=0.025$ \\
\hline Врачебный персонал & $r=-0.76, p=0.002$ \\
\hline Работники со стажем работы 10-15 лет & $r=-0.78, p=0.001$ \\
\hline Работники со стажем работы 20 лет и более & $r=-0.65, p=0.012$ \\
\hline
\end{tabular}

В группе руководителей и младшего медицинского персонала значимые корреляции мудрости и эмоционального выгорания отсутствуют. Причины отсутствия корреляции мудрости и эмоционального выгорания в «полярных» группах «Руководители» и «Младший медицинский персонал» мы видим в некоторых когнитивных, поведенческих особенностях их представителей. У руководителей меньше непосредственных контактов с больными, больше осознанности в работе, большая вариабельность принятия решений, меньше рутины и есть возможность переключиться на другой вид работы, чтобы снять эмоциональное напряжение. Для них характерна более творческая деятельность, больше ресурсов для исполнения решений и обязанностей. Высокий доход позволяет использовать более широкий спектр копинг-стратегий для поддержания эмоционального баланса. Мудрость руководителя будет проявляться, скорее всего, в принятии решений, а не в урегулировании своего эмоционального состояния. Поскольку мудрость не всегда может влиять на эмо- 
циональную саморегуляцию, нередким фактом является злоупотребление руководителями своим положением, проявляющееся в негативных эмоциональных реакциях в адрес подчиненных. Вероятно, у мудрого руководителя есть подсознательное понимание того, что защита в форме эмоционального выгорания (негативные эмоциональные реакции в адрес деловых партнеров, деперсонализация, тревога, депрессия, эмоциональная отстраненность и т. д.) приведет его к провалу в карьере.

В ситуации с младшим медицинским персоналом происходит противоположное: труд рутинный, исполнительский, низкооплачиваемый, ответственность только за свой объем работы. У большинства нет никаких экзистенциальных установок, связанных с профессиональной деятельностью. Они не сильно дорожат своим местом работы, меняя его с целью уйти от негативных влияний.

\section{Заключение}

Как показал теоретический анализ, важными ресурсами профилактики эмоционального выгорания медицинских работников являются позитивные характеристики личности, в частности мудрость. В отечественной науке и практике работа в этом направлении только начинается.

Анализ и обобщение результатов проведенного нами эмпирического исследования позволил сформулировать следующие выводы:

1) синдром эмоционального выгорания характерен более чем для половины обследованных медицинских работников, при этом он не зависит от возраста и стажа работы; более выражен у женщин, у группы среднего медицинского персонала (медицинских сестер);

2) уровень мудрости работников медицинской сферы не связан с возрастом, стажем работы; более высокий уровень мудрости характерен для руководителей медицинского учреждения, а также для мужской части выборки;

3) уровень мудрости и эмоциональное выгорание специалистов медицинской сферы являются взаимосвязанными феноменами - как правило, с повышением уровня мудрости происходит снижение уровня выраженности СЭВ.

Вместе с тем необходимо отметить некоторую ограниченность полученных выводов о характеристиках руководителей медицинского учреждения. Для повышения достоверности результатов в дальнейшем необходимо увеличить объем выборки управленцев.

Проведенное нами исследование показало, что чем более высоким уровнем мудрости обладает сотрудник медучреждения, тем меньше вероятность подверженности синдрому эмоционального выгорания. Мудрость помогает медицинскому персоналу противостоять синдрому эмоционального выгорания в любых его проявлениях, избегать защитных реакций, приводящих к негативным последствиям в работе, утрате здоровья, разочарованию в жизни, способствует преодолению стрессовых ситуаций в профессиональной среде.

В настоящее время сложилась уникальная ситуация, когда высочайшая нагрузка на сотрудников медицинских учреждений может вызывать эмоциональное выгорание в гораздо больших масштабах, чем ранее. Именно поэтому для профилактики кризисной ситуации главным врачам и организаци- 
онным психологам медучреждений необходимо задействовать не только внешние, например материальные, но и внутренние личностные ресурсы. Возможно, что именно мудрость будет важным фактором сохранения психического здоровья и профессионального долголетия. Не исключено, что и сама сложная ситуация пандемии окажет воздействие на становление или редукцию мудрости. Только дальнейшие эмпирические исследования позволят раскрыть динамику возникновения и развития мудрости, возможности ее целенаправленного формирования у медицинских работников.

Благодарности и финансирование. Исследование выполнено при финансовой поддержке Российского фонда фундаментальных исследований, в рамках научного проекта № 19-013-00849 «Мудрость как детерминанта решения сложных жизненных проблем».

\section{Список литературы}

Абдуллаева М.М. Личностные и организационные ресурсы профилактики выгорания медицинских работников хосписа // Выгорание и профессионализация: сб. науч. тр. / под ред. В.В. Лукьянова, А.Б. Леоновой, А.А. Обознова, А.С. Чернышева, Н.Е. Водопьяновой. Курск: Курск. гос. ун-т, 2013. С. 269-294.

Бектасова М.В., Капщов B.A., Шепарев А.А. Распространенность и характеристика синдрома «эмоционального выгорания» у медицинского персонала онкологических, фтизиатрических учреждений Приморского края // Гигиена и санитария. 2016. № 5. С. 60-62.

Бойко В.В. Синдром «эмоционального выгорания» в профессиональном общении. СПб., 1999.

Борисова О.Н., Токарев А.P., Троиџкий М.С. Профессиональный стресс у врачей (краткий обзор отечественной литературы) // Вестник новых медицинских технологий. 2019. № 6. https://doi.org/10.24411/2075-4094-2019-16569

Водопьянова Н.E. Теория и практика противодействия синдрому выгорания // Выгорание и профессионализация: сб. науч. тр. / под ред. В.В. Лукьянова, А.Б. Леоновой, А.А. Обознова, А.С. Чернышева, Н.Е. Водопьяновой. Курск: Курск. гос. ун-т, 2013. C. 294-324.

Водопьянова Н.Е., Старченкова Е.С. Синдром выгорания: диагностика и профилактика. СПб.: Питер, 2005. 336 с.

Водопьянова Н.Е., Шестакова К.Н. Позитивный подход к противодействию профессиональному выгоранию // Современные исследования социальных проблем. 2014. № 3 (35). C. 24.

Говорин Н.В., Бодагова Е.А. Синдром эмоционального выгорания у врачей // Оргздрав: Новости. Мнения. Обучение. Вестник ВШОУЗ. 2016. № 1 (3). С. 98-106.

Золотухина Л.В., Шадрина И.В. Синдром профессионального выгорания у психиатров и медперсонала психиатрических учреждений // Проблемы исследования синдрома «выгорания» и пути его коррекции у специалистов «помогающих» профессий (в медицинской, психологической и педагогической практике). Курск: КГУ, 2007. С. 62-65.

Зыкова 3.Н., Горбунова Л.А. Исследование синдрома эмоционального выгорания в группе врачей-стоматологов // Новая Наука: стратегии и векторы развития. 2016. № 118(3). C. 71-74.

Кобякова О.С., Деев И.А., Куликов Е.С., Хомяков К.В., Тюфилин Д.С., Загромова Т.А., Балаганская М.A. Профессиональное выгорание врачей различных специальностей // Здравоохранение Российской Федерации. 2017. Т. 61. № 6. С. 322-329. http://dx.doi.org/10.18821/0044-197X-2017-61-6-322-329

Леонтьев Д.А. Мудрость как интегральная характеристика личностного потенциала // Личностный потенциал: структура и диагностика / под ред. Д.А. Леонтьева. М.: Смысл, 2011. С. 92-106. 
Лукьянов B.B. Синдром выгорания и его взаимосвязь со структурой личности у врачейнаркологов // Современные проблемы исследования синдрома выгорания у специалистов коммуникативных профессий. Курск: КГУ, 2008. С. 198-213.

Мехтиханова Н.Н. Мудрость как научная категория // Психологические исследования интеллекта и творчества: материалы научной конференции, посвященной памяти Я.А. Пономарева и В.Н. Дружинина (ИП РАН, 7-8 октября 2010 г.). М.: Институт психологии РАН, 2010. С. 230-233.

Мехтиханова Н.Н., Смульсон М.Л. Мудрость - свойство пожилых и адаптированных? // Вестник Костромского государственного университета имени Н.А. Некрасова. 2013. № 3. C. 36-40.

Мурашкин М.С., Шаршакова Т.М. Синдром эмоционального выгорания в профессиональной деятельности врачей // Проблемы здоровья и экологии. 2020. Т. 64. № 2. С. 119-123.

Обознов А.А., Доценко О.Н. Эмоциональная направленность как фактор выгорания // Выгорание и профессионализация: сб. науч. тр. / под ред. В.В. Лукьянова, А.Б. Леоновой, А.А. Обознова, А.С. Чернышева, Н.Е. Водопьяновой. Курск: Курск. гос. ун-т, 2013. C. 164-178.

Орел В.Е. Синдром психического выгорания личности. М.: ИП РАН, 2005. 330 с.

Панкова С.Н., Азарова О.А., Кумирова О.А. Синдром эмоционального выгорания у врачейстоматологов // Научно-медицинский вестник Центрального Черноземья. 2019. № 76. C. 102-108.

Полунина O.B. К вопросу взаимосвязи профессионального выгорания и увлеченности работой // Выгорание и профессионализация: сб. науч. тр. / под ред. В.В. Лукьянова, А.Б. Леоновой, А.А. Обознова, А.С. Чернышева, Н.Е. Водопьяновой. Курск: Курск. гос. ун-т, 2013. С. 255-269.

Семенова Н.В., Вяльцин А.С., Авдеев Д.Б., Кузюкова А.В., Мартынова Т.С. Эмоциональное выгорание у медицинских работников // Современные проблемы науки и образования. 2017. № 2. С. 231-245.

Чутко Л.С., Козина Н.В. Синдром эмоционального выгорания: клинические и психологические аспекты. М.: МЕДпресс-информ, 2013. 256 с.

Ardelt M. Empirical assessment of a three-dimensional wisdom scale // Research on Aging. 2003. Vol. 25. No 3. Pp. 275-324. https://doi.org/10.1177/0164027503025003004

Baltes P.B., Smith J. The Fascination of Wisdom: Its Nature, Ontogeny, and Function // Perspectives on Psychological Science. 2008. Vol. 3. No 1. Pp. 56-64. https://doi.org/10.1111/j.17456916.2008.00062.x

Benner P. The wisdom of our practice // American Journal of Nursing. 2000. Vol. 100. No. 10. Pp. 99-105. https://doi.org/10.2307/3522335

Budziński W., Walkiewicz M., Tartas M. The system of values and styles of success in the medical career: A longitudinal study // International Journal of Occupational Medicine and Environmental Health. 2018. Vol. 31. No. 6. Pp. 823-835. https://doi.org/10.13075/ijomeh.1896.01298

Christley Y., McMillan L., McCallum L., O'Neill A. Practical wisdom in nursing practice: A concept analysis. 2012. URL: https://www.rcn.org.uk/_data/assets/pdf_file/0010/445816/Research2012Mo15.pdf

Clouston T.J. Pearls of wisdom: using the single case study or gem to identify strategies for mediating stress and work-life imbalance in healthcare staff // Journal of Research in Nursing. 2019. Vol. 24. No. 1-2. Pp. 61-72. https://doi.org/10.1177/1744987118809506

Csikszentmihalyi M., Seligman M.E. Positive psychology: An introduction // American Psychologist. 2000. Vol. 55. No. 1. Pp. 5-14.

Haggerty L.A., Grace P. Clinical wisdom: The essential foundation of "good" nursing care // Journal of Professional Nursing. 2008. Vol. 24. No. 4. Pp. 235-240. https://doi.org/10.1016/j.profnurs.2007.06.010

Hall G.S. Senescence: The last half of life. New York: D. Appleton and Company, 1922.

Kulatunga-Moruzi C., Norman G.R. Validity of admissions measures in predicting performance outcomes: The contribution of cognitive and non-cognitive dimensions // Teaching and Learning in Medicine. 2002. Vol. 14. Pp. 34-42. 
Levey J., Levey M. Mindful leadership for personal and organizational resilience // Clinical Radiology. 2019. Vol. 74. Pp. 739-745. https://doi.org/10.1016/j.crad.2019.06.026

Mangione S., Chakraborti C., Staltari G., Harrison R., Tunkel A.R., Liou K.T., ... Kahn M.J. Medical students' exposure to the humanities correlates with positive personal qualities and reduced burnout: a multi-institutional US survey // Journal of General Internal Medicine. 2018. Vol. 33. No. 5. Pp. 628-634. https://doi.org/10.1007/s11606-017-4275-8 Matney S.A., Brewster P.J., Sward K.A., Cloyes K.G., Staggers N. Philosophical approaches to the nursing informatics data-information-knowledge-wisdom framework // Advances in Nursing Science. Vol. 34. No. 1. Pp. 6-18. https://doi.org/10.1097/ANS.0b013e3182071813

Matney S.A., Maddox L.J., Staggers N. Nurses as knowledge workers: Is there evidence of knowledge in patient handoffs? // Western Journal of Nursing Research. 2014. Vol. 36. No. 2. Pp. 171-190. https://doi.org/10.1177/0193945913497111

Medical Professionalism: Best Practices / ed. by R.L. Byyny, M.A. Papadakis, D.S. Paauw. Menlo Park, CA: Alpha Omega Alpha Honor Medical Society, 2015. URL: http://alphaomegaalpha.org/pdfs/2015MedicalProfessionalism.pdf

Papagiannis A. Eliot's Triad: Information, Knowledge and Wisdom in Medicine // Hektoen International Journal of Medical Humanities. 2014. URL: http://hekint.org/2017/01/29/eliots-triad-information-knowledge-and-wisdom-in-medicine/

Price P.B., Lewis E.G., Loughmiller G.C., Nelson D.E., Murray S.L., Taylor C.W. Attributes of a good practicing physician // Academic Medicine. 1971. Vol. 46. No. 3. Pp. 229-237.

Rogers J.C., Coutts L. Do students' attitudes during preclinical years predict their humanism as clerkship students? // Academic Medicine. 2000. Vol. 75. No. 10. Pp. 74-77.

Shih E.C., Hou W.L., Lin P.L., Hsiao S.M., Sun C.A., Chou Y.C., Yang T. Personal Characteristics, Workplace Stressors, and Occupational Burnout among Psychiatric Nurses in Southern Taiwan - A Cross-sectional Study // Nursing and Health. 2016. Vol. 4. No. 2. Pp. 15-23. https://doi.org/10.13189/nh.2016.040201

Smith J.M. Surgeon Coaching: Why and How // Journal of Pediatric Orthopaedics. 2020. Vol. 40. Pp. 33-37. https://doi.org/10.1097/BPO.0000000000001541

Wang L., Wang H., Shao S., Jia G., Xiang J. 2020. Job Burnout on Subjective Well-Being Among Chinese Female Doctors: The Moderating Role of Perceived Social Support // Frontiers in Psychology. 2020. Vol. 11. https://doi.org/10.3389/fpsyg.2020.00435

\section{История статьи:}

Поступила в редакцию: 7 сентября 2020 г.

Принята к печати: 15 ноября 2020 г.

\section{Для цитирования:}

Мехтиханова Н.Н., Мурзина Ю.С., Русакова Ю.Е. Мудрость как фактор предотвращения эмоционального выгорания медицинских работников // Вестник Российского университета дружбы народов. Серия: Психология и педагогика. 2020. Т. 17. № 4. C. 685-704. http://dx.doi.org/10.22363/2313-1683-2020-17-4-685-704

\section{Сведения об авторах:}

Мехтиханова Наталья Николаевна, кандидат психологических наук, доцент, доцент кафедры общей психологии Ярославского государственного университета имени П.Г. Демидова (Ярославль, Россия). ORCID iD: https://orcid.org/0000-0002-1531-6265; eLIBRARY SPIN-код: 4878-2248. E-mail: natnik1@list.ru

Мурзина Юлия Сергеевна, кандидат психологических наук, доцент кафедры общей и социальной психологии Тюменского государственного университета (Тюмень, Россия). ORCID iD: https://orcid.org/0000-0002-8616-4422; eLIBRARY SPIN-код: 28826129; Scopus Author ID: 583010. E-mail: j.s.murzina@yandex.ru 
Русакова Юлия Евгеньевна, студентка Института психологии и педагогики, проходящая обучение по программе профессиональной переподготовки «Практический психолог», Тюменского государственного университета; специалист по кадрам сектора управления персоналом Областной клинической больницы (Тюмень, Россия). E-mail: yuliya-rus@mail.ru

DOI 10.22363/2313-1683-2020-17-4-685-704

Research article

\title{
Wisdom as a Factor in Preventing Emotional Burnout among Medical Professionals
}

\author{
Natalya N. Mekhtikhanova ${ }^{1}$, Julia S. Murzina ${ }^{2}$, Julia E. Rusakova ${ }^{2}$ \\ ${ }^{1}$ Yaroslavl Demidov State University \\ 14 Sovetskaya St, Yaroslavl, 150003, Russian Federation \\ ${ }^{2}$ Tyumen State University \\ 6 Volodarsky St, Tyumen, 625003, Russian Federation
}

\begin{abstract}
The authors of this article examine wisdom as an internal resource in a sample of medical workers that can prevent the development of unhealthy deviations and preserve professional and life longevity. The aim of this work was to study the relationship between wisdom and emotional burnout in medical personnel. The article provides a theoretical analysis of the study of emotional burnout in medical workers, offers a description of the phenomenon of wisdom, and describes foreign empirical research on wisdom in the medical field. To collect data, the authors used The Level of Wisdom Questionnaire by N.N. Mehtikhanova and The Inventory for Diagnosing Emotional Burnout by V.V. Boyko. An empirical study conducted with 184 employees of the Tyumen Regional Clinical Hospital found signs of emotional burnout in $53.8 \%$ of the respondents. A comparison of groups of the surveyed medical workers having different levels of emotional burnout revealed significant differences in terms of wisdom. A correlation analysis showed a negative relationship between wisdom and emotional burnout of the medical personnel $\left(r_{s}=-0.48, p<0.001\right)$. A comparison between the groups of male and female respondents showed significant differences in terms of wisdom $(U=1267.50, p=0.016)$ and in terms of emotional burnout $(U=1253.00, p=0.013)$ : wisdom was higher in the group of men, while emotional burnout was higher in the group of women. A pairwise comparison using the Mann - Whitney $U$-test revealed differences in wisdom between the groups of junior medical personnel and managers $(U=31.00, p=0.007)$ as well as between the groups of nurses and managers $(U=326.00, p<0.001)$. Wisdom in both cases was higher for the group of managers. In sum, results of this study found that wisdom helps medical personnel resist burnout syndrome. The formation of this quality will help medical workers to better preserve their mental health and professional longevity.
\end{abstract}

Key words: wisdom, emotional burnout, age differences, gender differences, senior and junior medical personnel

Acknowledgements and Funding. The research was carried out with the financial support of the Russian Foundation for Basic Research, as part of the scientific project No. 19-013-00849 "Wisdom as a determinant of solving complex life problems". 


\section{References}

Abdullayeva, M.M. (2013). Personal and organizational resources for prevention of burnout of hospice medical workers. In V.V. Lukyanov, A.B. Leonova, A.A. Oboznov, A.S. Chernyshev, \& N.E. Vodopyanova (Eds.), Burnout and professionalization (pp. 269-294). Kursk: Kursk State University Publ. (In Russ.)

Ardelt, M. (2003). Empirical assessment of a three-dimensional wisdom scale. Research on Aging, 25(3), 275-324. https://doi.org/10.1177/0164027503025003004

Baltes, P.B., \& Smith, J. (2008). The Fascination of Wisdom: Its Nature, Ontogeny, and Function. Perspectives on Psychological Science, 3(1), 56-64. https://doi.org/10.1111/j.17456916.2008.00062.x

Bektasova, M.V., Kaptsov, V.A., \& Sheparev, A.A. (2016). Prevalence and characteristics of the "emotional burnout" syndrome in medical personnel of oncological and phthisiological institutions of the Primorsky territory. Hygiene and Sanitation, (5), 60-62. (In Russ.)

Benner, P. (2000). The wisdom of our practice. American Journal of Nursing, 100(10), 99-105. https://doi.org/10.2307/3522335

Borisova, O.N., Tokarev, A.R., \& Troitsky, M.S. (2019). Professional stress in doctors (a brief review of domestic literature). Bulletin of New Medical Technologies. Journal of New Medical Technologies, (6). (In Russ.) https://doi.org/10.24411/2075-4094-2019-16569

Boyko, V.V. (1999). Burnout syndrome in professional communication. Saint Petersburg: Piter Publ. (In Russ.)

Budziński, W., Walkiewicz, M., \& Tartas, M. (2018). The system of values and styles of success in the medical career: A longitudinal study. International Journal of Occupational Medicine and Environmental Health, 31(6), 823-835. https://doi.org/10.13075/ijomeh.1896.01298

Byyny, R.L., Papadakis, M.A., \& Paauw D.S. (Eds.). (2017). Medical professionalism: Best practices. Menlo Park, CA: Alpha Omega Alpha Honor Medical Society. Retrieved from http://alphaomegaalpha.org/pdfs/2015MedicalProfessionalism.pdf

Christley, Y., McMillan, L., McCallum, L., \& O’Neill, A. (2012). Practical wisdom in nursing practice: A concept analysis. Retrieved from https://www.rcn.org.uk/_data/assets/pdf_file/0010/445816/Research2012Mo15.pdf

Chutko, L.S., \& Kozina, N.V. (2013). Emotional burnout Syndrome. Clinical and psychological aspects. Moscow: Medpress-inform Publ. (In Russ.)

Clouston, T.J. (2019). Pearls of wisdom: Using the single case study or gem to identify strategies for mediating stress and work-life imbalance in healthcare staff. Journal of Research in Nursing, 24(1-2), 61-72. https://doi.org/10.1177/1744987118809506

Csikszentmihalyi, M., \& Seligman, M.E. (2000). Positive psychology: An introduction. American Psychologist, 55(1), 5-14.

Govorin, N.V., \& Bodagova, E.A. (2016). Burnout syndrome in doctors. Orgzdrav: News. Opinions. Training. Bulletin VSHOUZ, 1(3), 98-106. (In Russ.)

Haggerty, L.A., \& Grace, P. (2008). Clinical wisdom: The essential foundation of "good" nursing care. Journal of Professional Nursing, 24(4), 235-240. https://doi.org/10.1016/j.profnurs.2007.06.010

Hall, G.S. (1922). Senescence: The last half of life. New York: D. Appleton and Company.

Kobyakova, O.S., Deev, I.A., Kulikov, E.S., Khomyakov, K.V., Tyufilin, D.S., Zagromova, T.A., \& Balaganskaya, M.A. (2017). Professional burnout of doctors of various specialties. Healthcare of the Russian Federation, 61(6), 322-329. (In Russ.) http://dx.doi.org/10.18821/0044-197X-2017-61-6-322-329

Kulatunga-Moruzi, C., \& Norman, G.R. (2002). Validity of admissions measures in predicting performance outcomes: The contribution of cognitive and non-cognitive dimensions. Teaching and Learning in Medicine, 14(1), 34-42.

Leontiev, D.A. (2011). Wisdom as an integral characteristic of personal potential. In D.A. Leontiev (Ed.), Personal potential: structure and diagnostics (pp. 92-106). Moscow: Smysl Publ. (In Russ.)

Levey, J. \& Levey, M. (2019). Mindful leadership for personal and organizational resilience. Clinical Radiology, 74, 739-745. https://doi.org/10.1016/j.crad.2019.06.026 
Lukyanov, V.V. (2008). Burnout Syndrome and its relationship with the personality structure of narcologists. In Modern problems of research of burnout syndrome in specialists of communicative professions (pp. 198-213). Kursk: Kursk State University Publ. (In Russ.)

Mangione, S., Chakraborti, C., Staltari, G., Harrison, R., Tunkel, A.R., Liou, K.T., ... \& Kahn M.J. (2018). Medical students' exposure to the humanities correlates with positive personal qualities and reduced burnout: a multi-institutional US survey. Journal of General Internal Medicine, 33(5), 628-634. https://doi.org/10.1007/s11606-017-4275-8

Matney, S.A., Brewster, P.J., Sward, K.A., Cloyes, K.G., \& Staggers, N. (2011). Philosophical approaches to the nursing informatics data-information-knowledge-wisdom framework. Advances in Nursing Science, 34(1), 6-18. https://doi.org/10.1097/ANS.0b013e3182071813

Matney, S.A., Maddox, L.J., \& Staggers, N. (2014). Nurses as knowledge workers: Is there evidence of knowledge in patient handoffs? Western Journal of Nursing Research, 36(2), 171-190. https://doi.org/10.1177/0193945913497111

Mekhtikhanova, N.N. (2010). Wisdom as a scientific category. In Psychological research of intelligence and creativity: Proceedings of conference dedicated to the memory of Y.A. Ponomarev and V.N. Druzhinin (pp. 230-233). Moscow: Institute of Psychology RAS Publ. (In Russ.)

Mekhtikhanova, N.N., \& Smulson, M.L. (2013). Is wisdom a property of the elderly and the adapted? Bulletin of the Kostroma State University, (3), 36-40. (In Russ.)

Murashkin M.S., \& Sharshakova, T.M. (2020). Emotional burnout Syndrome in the professional activity of doctors. Health and Environmental Issues, 64(2), 119-123. (In Russ.)

Oboznov A.A., \& Dotsenko, O.N. (2013). Emotional orientation as a burnout factor. In V.V. Lukyanov, A.B. Leonova, A.A. Oboznov, A.S. Chernyshev, N.E. Vodopyanova (Eds.), Burnout and professionalization (pp. 164-178). Kursk: Kursk state University Publ. (In Russ.)

Orel, V.E. (2005). Syndrome of mental burnout of the personality. Moscow: Institute of Psychology RAS Publ. (In Russ.)

Pankova, S.N., Azarova, O.A., \& Kumirova, O.A. (2019). Syndrome of emotional burnout in dentists. Scientific and Medical Bulletin of the Central Chernozem region, (76), 102-108. (In Russ.)

Papagiannis, A. (2017). Eliot's Triad: Information, Knowledge and Wisdom in Medicine. Hektoen International Journal of Medical Humanities. http:/hekint.org/2017/01/29/eliots-triad-information-knowledge-and-wisdom-in-medicine/

Polunina, O.V. (2013). On the relationship between professional burnout and work passion. In V.V. Lukyanov, A.B. Leonova, A.A. Oboznov, A.S. Chernyshev, \& N.E. Vodopyanova (Eds.), Burnout and professionalization (pp. 255-269). Kursk: Kursk State University Publ. (In Russ.)

Price, P.B., Lewis, E.G., Loughmiller, G.C., Nelson, D.E., Murray, S.L., \& Taylor, C.W. (1971). Attributes of a good practicing physician. Academic Medicine, 46(3), 229-237.

Rogers J.C., \& Coutts, L. (2000). Do students' attitudes during preclinical years predict their humanism as clerkship students? Academic Medicine, 75(10), 74-77.

Semenova, N.V., Vyaltsin, A.S., Avdeev, D.B., Kuzyukova, A.V., \& Martynova, T.S. (2017). Emotional burnout in medical workers. Modern Problems of Science and Education, (2), 231-245. (In Russ.)

Shih, E.C., Hou, W.L., Lin, P.L., Hsiao, S.M., Sun, C.A., Chou, Y.C., \& Yang, T. (2016). Personal Characteristics, Workplace Stressors, and Occupational Burnout among Psychiatric Nurses in Southern Taiwan - A Cross-sectional Study. Nursing and Health, 4(2), 15-23. https://doi.org/10.13189/nh.2016.040201

Smith, J.M. (2020). Surgeon Coaching: Why and How. Journal of Pediatric Orthopaedics, 40, 33-37. https://doi.org/10.1097/BPO.0000000000001541

Vodopyanova, N.E. (2013). Theory and practice of countering burnout syndrome. In V.V. Lukyanov, A.B. Leonova, A.A. Oboznov, A.S. Chernyshev, \& N.E. Vodopyanova (Eds.), Burnout and professionalization (pp. 294-324). Kursk: Kursk State University Publ. (In Russ.) 
Vodopyanova, N.E., \& Shestakova, K.N. (2014). Positive approach to counteracting professional burnout. Modern Research on Social Problems, 3(35), 24. (In Russ.)

Vodopyanova, N.E., \& Starchenkova, E.S. (2005). Burnout Syndrome: Diagnostics and prevention. Saint Petersburg: Piter Publ. (In Russ.)

Wang, L., Wang, H., Shao, S., Jia, G., \& Xiang, J. (2020). Job Burnout on Subjective WellBeing Among Chinese Female Doctors: The Moderating Role of Perceived Social Support. Frontiers in Psychology, 11. https://doi.org/10.3389/fpsyg.2020.00435

Zolotukhina, L.V., \& Shadrina, I.V. (2007). Professional burnout syndrome in psychiatrists and medical staff of psychiatric institutions. In Problems of research of "burnout" syndrome and ways of its correction in specialists of "helping" professions (in medical, psychological and pedagogical practice) (pp. 62-65). Kursk: Kursk State University Publ. (In Russ.)

Zykova, Z.N., \& Gorbunova, L.A. (2016). Study of emotional burnout syndrome in a group of dentists. New Science: Strategies and Vectors of Development, 118(3), 71-74. (In Russ.)

Article history:

Received: 7 September 2020

Revised: 30 October 2020

Accepted: 15 November 2020

\section{For citation:}

Mekhtikhanova, N.N., Murzina, J.S., \& Rusakova, J.E. (2020). Wisdom as a Factor in Preventing Emotional Burnout among Medical Professionals. RUDN Journal of Psychology and Pedagogics, 17(4), 685-704. (In Russ.) http://dx.doi.org/10.22363/2313-1683-202017-4-685-704

\section{Bio notes:}

Natalya N. Mekhtikhanova, Ph.D. in Psychology, is Associate Professor of the General Psychology Department of Yaroslavl Demidov State University (Yaroslavl, Russia). ORCID iD: https://orcid.org/0000-0002-1531-6265; eLIBRARY SPIN-code: 4878-2248. E-mail: natnik1@list.ru

Julia S. Murzina, Ph.D. in Psychology, is Associate Professor of Department of General and Social Psychology of University of Tyumen (Tyumen, Russia). ORCID iD: https://orcid.org/0000-0002-8616-4422; eLIBRARY SPIN-code: 2882-6129; Scopus Author ID: 583010. E-mail: j.s.murzina@yandex.ru

Julia E. Rusakova is student of the professional retraining program "Practical Psychologist" at the Institute of Psychology and Pedagogy of Tyumen State University; HR specialist of the Personnel Management Department of the Regional Clinical Hospital (Tyumen, Russia). E-mail: yuliya-rus@mail.ru 